\title{
PRESERVANDO A RELAÇÃO COM OS/AS DESCENDENTES MENORES: PADRÕES DE COMUNICAÇÃO NA MATERNIDADE E PATERNIDADE EM RECLUSÃO
}

Catarina Vieira, Luísa Saavedra e Alexandra M. Araújo

Escola de Psicologia, Universidade do Minho, Portugal Instituto de Educação, Universidade do Minho, Portugal

\section{Resumo}

Tendo em conta o elevado número de pais e mães em reclusão e comprovada a importância da comunicação entre progenitores/as em reclusão e seus/suas descendentes, o presente estudo visou avaliar a frequência de comunicação estabelecida entre pais e mães em reclusão e seus/suas descendentes menores, a perceção da qualidade da relação e a competência parental percebida por parte destas figuras. Foi administrado um questionário, construído para o efeito deste estudo, a 100 mães e 100 pais a cumprirem pena prisional. Para além dos maiores obstáculos enfrentados pelas mães devido à maior distância geográfica dos descendentes, os resultados registam, também, diferenças relativas aos papéis socialmente atribuídos à maternidade e paternidade.

Palavras-chave: pais/mães encarcerados, obstáculos à comunicação, qualidade da relação percebida, competência parental percebida, visitas prisionais.

\begin{abstract}
Preserving the relationship with children: patterns of communication in motherhood and fatherhood in reclusion

Given the high number of incarcerated fathers and mothers and the proven importance of communication between parents in reclusion and their descendants, the present study aimed to assess the frequency of communication between fathers and mothers in prison and their minor offspring, the perception of quality in the relationship and perceived parental competence, by these figures. A questionnaire constructed for the purposes of this study was administered to 100 mothers and 100 fathers with a prison sentence. In addition to the major obstacles faced by mothers due to the increased geographical distance of their descendants, results also suggested differences concerning the socially assigned roles of motherhood and fatherhood.
\end{abstract}

Keywords: incarcerated parents, obstacles to communication, perceived quality in relationship, perceived parental competence, prison visits.

\section{Resumen}

Preservación de la relación con los descendientes menores: patrones de comunicación en la maternidad y la paternidad en reclusión

Dado el elevado número de padres y madres encarcelados y comprobada la importancia de la comunicación entre los padres y madres en la prisión y sus descendientes, el presente estudio tuvo como objetivo evaluar la frecuencia de la comunicación que se establece entre padres y madres en la cárcel y su descendencia menor, la percepción de calidad de la relación y competencia parental percibida por estes padres y madres. Se administró un cuestionario, construido para el estudio, a 100 madres y 100 padres a cumplir pena de prisión. Además de los principales obstáculos que enfrentan las madres debido al aumento de la distancia geográfica de los descendientes los resultados también 
presentan diferencias a respecto de las funciones socialmente asignadas de la maternidad y la paternidad.

Palabras-clave: los padres/madres encarcelados, los obstáculos de comunicación, la percepción de calidad, relación de competencia parental percibida, visitas a las cárceles.

\section{Introdução}

Dados do Centro Internacional de Estudos Prisionais revelam que a população recluída tem vindo a crescer consideravelmente, em todo o mundo, ao longo das últimas décadas. As mulheres representam uma minoria quando comparadas com os homens, ainda que a sua prevalência carcerária tenha, igualmente, aumentado ao longo dos anos (Walmsley, 2013). Ora, este acréscimo da população encarcerada, entre outras implicações, resulta num inequívoco aumento do número de pais e mães em prisão (Mumola, 2000; Glaze e Maruschak, 2008), bem como do número de filhos e filhas com, pelo menos, um/a dos/as progenitores/as detidos (Murray, Farrington, Sekol e Olsen, 2009). Dados da The Quaker Council for European Affairs (2007) indicam que a percentagem de mães encarceradas em 2005 rondava os 57.7\% na Dinamarca, 75.6\% na Grécia, e 81.9\% em Espanha. Em contrapartida, nos Estados Unidos da América a percentagens de pais encarcerados era de 92\%, em 2007, e em Portugal, no ano de 2005, estimava-se que 15,895 crianças tivessem o pai em reclusão e 1,196 crianças a mãe na mesma situação (Rosenberg, 2009).

Como a atribuição geral das funções parentais recai essencialmente nas mulheres, estas, quando em reclusão, recebem mais atenção por parte da investigação, comparativamente com o que ocorre para os homens. No entanto, dado a importância cada vez maior que a figura paterna vem ocupando na realidade internacional (Wall, 2010; Glauber e Gozjolko, 2011) e portuguesa (Aboim, 2010) é essencial que, também em meio privativo de liberdade, estas figuras sejam tidas em conta (Magaletta e Herbst, 2001; Rosenberg, 2009; Machado e Granja, 2013). Assim, pelo bem das crianças e, a longo prazo, para bem da sociedade, importa estimular investigação que possa vir a contribuir para mudanças nas políticas e nas práticas, sem descurar todo o cuidado às mães reclusas e às crianças que vivem extramuros ou em confinamento com elas. É de salientar que na maior parte dos países em que está prevista a possível vivência de uma criança com o pai recluso (em Portugal esta possibilidade é estipulada pela Lei n.o 115/2009), essa situação não se tem verificado até ao momento, ao contrário do que acontece com as mães, na maior parte dos países (Rosenberg, 2009; Machado e Granja, 2013).

Este duplo-padrão de género (Rosenberg, 2009), relativamente aos pais e mãe reclusas, parece reforçar normas que fora do contexto prisional são, atualmente, questionadas (Glauber e Gozjolko, 2011; Machado e Granja, 2013). É certo que historicamente se espera que a mulher concretize a maternidade e que seja 
afetuosa, carinhosa e terna, assegurando o papel de principal cuidadora das suas crianças (e.g., Rich, 1976; Badinter, 1985). No entanto, a velha figura do homem como provedor do lar tem sido destituída pela paridade conjugal e pelo questionamento das masculinidades tradicionais, dando origem uma figura parental cada vez mais participativa e afetiva no âmbito familiar (Wall, Aboim e Marinho, 2007; Collier e Sheldon, 2008). Mas se estes estereótipos estão em desconstrução na sociedade (Aboim, 2010; Glauber e Gozjolko, 2011), importa que sejam também implementados com aqueles e aquelas que se encontram socialmente segregados na prisão.

Efetivamente, as investigações internacionais têm demonstrado a importância das relações parentais, que amenizam as potenciais consequências negativas inerentes à reclusão para ambas as partes, isto é, progenitores/as e descendentes (Novais, Ferreira e Santos, 2006). Como principais implicações perniciosas para os homens detidos e mulheres detidas refira-se uma total transformação do quotidiano (e.g., cumprimento das políticas e regras prisionais), a privação da liberdade e, em muitos casos, a separação dos/as filhos/as menores (Snyder, Carlo e Coats, 2001). Por seu turno, os/as filhos/as dos/as reclusos/as são frequentemente sujeitos a alterações de residência e de estabelecimento de ensino, modificações na estrutura familiar e cuidados de que são alvo (Miller, 2006; Geller, Garfinkel, Cooper e Mincy, 2009), dificuldades económicas, já que muitos dos membros detidos asseguravam o sustento da família (Cunningham e Baker, 2003; Chui, 2010) e estigmatização e discriminação, sobretudo no contexto escolar (Chui, 2010; Dallaire, Ciccone e Wilson, 2010; Philips e Gates, 2011), resultando em fraco desempenho académico, problemas de comportamento e delinquência juvenil (Maldonado, 2006).

Em contrapartida, o contacto regular com as/os progenitoras/es poderá revelar-se um fator de proteção para o bem-estar psíquico de ambas as partes, com evidentes benefícios sociais (Maldonado, 2006; Snyder et al., 2001). Assim, estudos prévios sugerem que indivíduos que mantêm uma relação próxima com as/os suas/seus descendentes, durante a reclusão, têm menores dificuldades de adaptação à vida prisional (Lanier, 1993), menos problemas comportamentais durante o cumprimento da pena (Tebo, 2006), menos dificuldades na reintegração social, aquando da saída em liberdade, menores índices de sintomatologia psicopatológica (e.g., depressão, ansiedade) no decorrer da pena (Lanier, 1993) e menor propensão a reincidir no crime (Maldonado, 2006). A relação e comunicação frequente ajuda, igualmente, as/os menores a ultrapassar as dificuldades da separação (Tuerk e Loper, 2006) e a lidar com as dificuldades suprarreferidas.

As visitas, telefonemas e correspondência são as três modalidades de comunicação previstas entre prisioneiros e o exterior (Magaletta e Herbst, 2001). Cada uma delas apresenta vantagens e restrições de determinada ordem, que importa clarificar. Assim, se as visitas são a única forma de relação que possibilita aos intervenientes o contacto físico (Folk, Nichols, Dallaire e Loper, 2012), 
requerem um maior dispêndio de tempo e de recursos financeiros para as/os visitantes que, por norma, enfrentam já dificuldades financeiras. Por outro lado, para uma criança, o ambiente que se faz sentir em toda a esfera prisional, aquando da sua visita ao progenitor/a, nem sempre é o mais adequado (Folk et al., 2012). Além disso, existem restrições numéricas e temporais às visitas. Em Portugal, o Regulamento Geral dos Serviços Prisionais consubstancia que a população prisional poderá beneficiar de duas visitas semanais, com a duração máxima de uma hora cada, e poderá receber, no máximo, três pessoas, não sendo este limite abrangente a crianças com idade inferior a três anos (Decreto-Lei n. ${ }^{\circ}$ 51/2011, de 11 de abril).

Por seu turno, os telefonemas permitem que as figuras parentais se mantenham a par e participem do quotidiano da sua prole, ainda que não os possam ver ou tocar. Esta estratégia comunicacional traz a vantagem de um custo monetário inferior (em comparação às visitas) e da sua abrangência a crianças de quase todas as faixas etárias (Tuerk e Loper, 2006; Folk et al., 2012). Por outro lado, às chamadas telefónicas é imposto um limite temporal, que em Portugal se define na possibilidade de efetuar duas chamadas telefónicas diárias, com a duração máxima de cinco minutos cada. Salienta-se que a população prisional poderá fazer, mas não receber, telefonemas (Decreto-Lei n. ${ }^{\circ}$ 51/2011, de 11 de abril).

Por sua vez, a correspondência é uma forma de comunicação indireta (Folk et al., 2012), monetariamente mais acessível, e na qual não estão envolvidos condicionamentos temporais e de frequência, quer a nível do envio, quer ao nível da receção, permitindo ainda que o destinatário guarde e releia este documento no futuro (Tuerk e Loper, 2006). Em Portugal, não está estabelecido um limite máximo diário de envio e/ou receção de correspondência por parte do/a prisioneiro/a (Decreto-Lei n. ${ }^{\circ}$ 51/2011, de 11 de abril).

São poucos os estudos que comparam homens e mulheres recluídos ao nível da frequência e qualidade de comunicação com as/os filhas/os menores e os resultados nem sempre são coincidentes. Alguns estudos anglo-saxónicos demonstraram que pais recluídos têm menores níveis de contacto com os/as filhos/as menores, do que as mães (Glaze e Maruschak, 2008; Loper, Carlson, Levitt e Scheffel, 2009) e outras investigações indicaram que, quer homens, quer mulheres contactam com relativa frequência com as/os filhas/os menores e, ainda, que ambos têm perceções muito positivas dessa relação (Lee, Sansone, Swanson e Tatum, 2012; Mignon e Ransford, 2012; Swanson, Lee, Sansone e Tatum, 2012).

À exceção de parcos estudos de âmbito nacional (Cunha, 1994; Serras e Pires, 2004), são escassos os trabalhos nesta área, especialmente se tivermos em conta a inclusão das figuras masculinas, com algumas recentes exceções (Granja, Cunha e Machado, 2013; Machado e Granja, 2013). Assim, com este trabalho procura-se, por um lado, alargar o conhecimento na área, nomeadamente relativamente aos pais reclusos. Por outro lado, espera-se lançar um desafio às políticas prisionais na promoção da igualdade de género relativamente às práticas parentais. Para tal, o presente estudo tem como principal objetivo comparar padrões de 
comunicação e competência parental percebida entre reclusos e reclusas. Para o efeito, levantaram-se as seguintes questões de investigação: (i) Com quem viviam e vivem atualmente as/os menores; (ii) Qual o tipo de comunicação mais utilizada entre a população reclusa e suas/seus descendentes e qual a preferida; (iii) Quais os maiores obstáculos à comunicação e contacto; (iv) Qual a qualidade percebida da relação, prévia e atual à reclusão, com os/as filhos/as menores; e (v) Qual o nível de competência parental percebida e, nomeadamente, se a frequência de comunicação interfere com a perceção de eficácia parental.

\section{Participantes}

A amostra deste estudo, constituída por conveniência, foi recolhida em quatro Estabelecimentos Prisionais (E.P.) do Distrito Judicial do Porto (um estabelecimento feminino e três masculinos), e incluiu 200 reclusos/as, fazendo-se constituir por 50\% homens e 50\% mulheres, com idades compreendidas entre os 19 e os 59 anos de idade $(M=35.34, D P=7.73)$. O tempo de condenação destes/as oscilava entre os 2 e os 276 meses $(M=82.34, D P=54.09)$. No que diz respeito ao número de menores, cada recluso tinha em média 2 menores $(D P=1.19)$, num total de 393, variando este número, por recluso/a, entre 1 e 8 . Por seu turno, a idade dos menores variava entre os 0.25 e os 17 anos, sendo a média de 9 anos de idade $(D P=4.65)$.

No que concerne ao estado civil, a maioria (30.5\%) vive em união de facto, seguido dos/as solteiros/as $(26.5 \%)$ e igual percentagem de casados/as e divorciados/as (20.5\%). Restam $2 \%$ de pessoas viúvas. A maioria da população que participou no estudo era caucasiana e apenas três participantes eram de origem africana.

Em concordância com resultados de outros estudos (e. g. Wacquant, 2004), trata-se de uma população pouco escolarizada, apresentando a maioria (31\%) o $2^{\circ}$ ciclo do ensino básico, seguido de $28 \%$ com o $1^{\circ}$ ciclo. Em pontos extremos, refira-se a inclusão de $9 \%$ de pessoas sem literacia, $15 \%$ com o ensino secundário e $1.5 \%$ com ensino superior.

Tomaram-se como critérios de inclusão na amostra que cada sujeito: fosse homem ou mulher com condenação; tivesse, pelo menos, um/a filho/a menor de idade; que habitasse no exterior do estabelecimento prisional; fosse de nacionalidade portuguesa e participasse voluntariamente na investigação. Esta amostra representa $1.52 \%$ do total de população encarcerada

\section{Recolha dos dados}

Foi construído um questionário para o efeito deste estudo, atendendo aos objetivos e questões de investigação e à revisão bibliográfica da área. O questio- 
nário foi composto por um total de 26 questões de resposta fechada, de escolha múltipla com categorias mutuamente exclusivas. Um primeiro conjunto de questões pretendia fazer a caraterização sociodemográfica do/a participante (e.g. sexo, idade, raça/etnia, nível de escolaridade), bem como a constituição da família (e.g. número de filhos/as, sexo, idade). Um segundo conjunto de questões avaliava: o tipo e frequência de comunicação entre o/a recluso/a e os filhos/as menores; a forma de comunicação preferencial e a sua importância percebida para a manutenção da relação; a qualidade percebida desta relação na atualidade e previamente à reclusão; a existência, ou não, de obstáculos à comunicação entre progenitura e descendência; a situação atual de residência dos/as menores, bem como a qualidade percebida da relação do/a progenitor/a com o atual cuidador dos/as filhos/as menores; e a competência percebida face à parentalidade.

Este questionário foi administrado individualmente através de participação voluntária, após esclarecimento sobre os objetivos do estudo e assinatura da declaração de consentimento informado onde se assegurava o anonimato dos dados. Os dados foram estatisticamente tratados com recurso ao software IBM SPSS, versão 20 .

Os resultados serão apresentados pela mesma ordem das questões de investigação.

\section{Com quem viviam e vivem atualmente os/as menores}

No que diz respeito à primeira questão deste estudo ( $C$ Com quem vivem atualmente os seus filhos/as menores?») aferiu-se que a generalidade das pessoas participantes vivia com as/os descendentes antes da reclusão, ainda que tal se verifique maioritariamente no caso das mulheres (86\%). Atualmente, estas crianças e jovens vivem, na sua maioria $(47.5 \%)$, com o/a progenitor/a não recluído. Contudo, são de salientar diferenças significativas do ponto de vista do sexo. Assim, se por um lado $80 \%$ dos reclusos apontam as mães enquanto atuais cuidadoras, as reclusas, por seu turno, designam com maior frequência (45\%) os/as avôs/avós como cumprindo este papel, em detrimento dos pais (15\%). Na verdade, as mães reclusas recorrem mais frequentemente às figuras familiares para além dos avós (25\%) do que os pais (4\%).

\section{Tipo de comunicação mais frequente}

Neste ponto os dados irão detalhar, quer a tipologia de comunicação efetivamente realizada, quer a tipologia preferencial. Assim, quanto à forma de comunicação mais frequentemente usada entre a população encarcerada e suas crianças e adolescentes menores (em que o nível de frequência variava entre o 
«nunca», «entre 1 a 11 vezes por mês», "pelo menos 1 vez por mês», "pelo menos 1 vez por semana» e «todos ou quase todos os dias») destacam-se os telefonemas, em primeiro lugar (76\% todos os dias ou quase), seguidos das visitas (pelo menos $35.5 \% 1$ vez por semana e $27 \%$ pelo menos 1 vez por mês) e, finalmente, as cartas (21\% pelo menos 1 vez por mês).

Assim, e ainda que a correspondência seja a forma de comunicação menos usada pelos detidos e detidas, há que salvaguardar a existência de diferenças significativas entre homens e mulheres a este nível, sendo que estas enviam correspondência às/aos suas/seus filhas/os com maior frequência $(U=3104.00, p \leq .001)$ e tendem, também, a receber com maior regularidade correspondência $(U=$ 4222.00, $p=.054)$. A explicação para a menor utilização deste tipo de comunicação poderá estar relacionada com o baixo nível de literacia dos/as reclusos/as, observando-se que $45 \%$ do total de participantes nunca enviou uma carta aos menores e também devido a uma tendência geral da população para cada vez menos recorrer a este meio.

Relativamente aos telefonemas, a maioria das mães $(76 \%)$ e dos pais $(69 \%)$ contacta telefonicamente os/as filhos/as com frequência diária ou quase diária e recebe visitas semanais em 35\% dos casos. E embora a percentagem das mães (24\%) seja inferior à dos pais (30\%), estas diferenças que não são estatisticamente significativas. De salientar ainda que $21 \%$ das mães e $18 \%$ dos pais nunca recebem visitas dos/as seus/suas descendentes.

Embora os telefonemas sejam a comunicação mais frequente, a preferência de contacto recai sobre a visita (79\% para as mães e $78 \%$ para os pais), sendo a percentagem desta preferência equivalente tanto para homens como para mulheres. As visitas são um meio de colmatar, quer o isolamento familiar, quer de quebrar a rotina que caracteriza o ambiente prisional (Goffman, 1961). Ao mesmo tempo, tal como indica o trabalho de Rafaela Granja, Manuela Cunha e Helena Machado (2013) a reclusão pode reconfigurar as relações sobretudo com a figura paterna, pois os homens passam a ter a disponibilidade que, muitas vezes, não possuíam no exterior. Neste quadro de preferências apenas $2 \%$ de reclusos-pais referiram a correspondência como preferencial.

No que diz respeito ao desejo de comunicar com maior frequência com as/os descendentes menores, $95 \%$ das mães e $87 \%$ dos pais salientarem a vontade por uma comunicação mais intensa. Importa referir, ainda, que a totalidade da amostra considerou importante o contacto dos reclusos com as/os filhas/os. A teoria acerca do impacto positivo do suporte social (Sarason, Levine, Basham, e Sarason, 1983; Cohen e Wills, 1985; Cutrona, Cole, Colangelo, Assouline, e Russel, 1994) poderá ajudar na compreensão destes dados. Homens e mulheres necessitam e recorrem ao suporte das/os filhas/os, nesta situação de crise e potencialmente causadora de desajustamento psicológico, que representa a pena privativa de liberdade. A perceção de suporte social constitui-se, assim, como um atenuador da vivência de ansiedade e de stress, sendo igualmente vista como um potenciador do ajustamento psicológico e promotor do bem-estar geral do indiví- 
duo. Este suporte terá efeitos positivos na manutenção do ajustamento psicológico destes reclusos/as, com um potencial impacto positivo numa futura reintegração na vida social e laboral ativa, após a reclusão.

\section{Obstáculos à comunicação}

Para a avaliação de obstáculos à comunicação foram dadas como possibilidade de resposta as dificuldades económicas, as políticas prisionais, a distância geográfica, a má relação com o atual cuidador e outros obstáculos. Avaliou-se, ainda, a inexistência de obstáculos. O valor mais elevado $(40.5 \%)$ recaiu sobre as «políticas prisionais», ainda que esta percentagem seja maior no caso das reclusas (53\%), do que no caso dos homens (28\%). Tal poderá ser explicado por uma maior rigidez no cumprimento do Regulamento Geral dos Estabelecimentos Prisionais (Decreto-Lei n.o 51/2011, de 11 de abril) no E.P. para mulheres, resultando num máximo de duas chamadas diárias, com a duração máxima de 5 minutos cada.

Em contrapartida, em dois dos restantes E.P. masculinos não eram cumpridas tais normas. Nestes EPs houve um número representativo (17\%) de participantes a declarar a inexistência de obstáculos, nomeadamente a flexibilidade nas comunicações telefónicas diárias.

Ainda no que diz respeito aos obstáculos, é de salientar a importância da distância geográfica, particularmente visível no caso das mulheres reclusas. Verifica-se uma associação significativa entre a frequência de visitas que as reclusas recebem e o facto de residirem, ou não, no mesmo distrito do E.P. $\left({ }^{-2}(3)=22.06, p\right.$ $\leq .001)$. Enquanto para aquelas que residem no mesmo distrito do E.P., a maioria $(60 \%)$ recebe visitas dos/as filhos/as menores pelo menos uma vez por semana, das que residem num distrito diferente do E.P., a maioria $(30.8 \%)$ recebe visitas destes entre uma a onze vezes por ano. Em contrapartida, estes fatores não estão relacionados no caso dos homens $\left({ }^{-2}(3)=5.67, p=.13\right)$. Tal poderá justificar-se pelo facto das prisões femininas existirem em número manifestamente inferior aos E.P. masculinos (um no Norte, outro no Centro-Sul e outro no Sul do País), implicando uma maior distância a ser percorrida e consequentemente, um maior gasto financeiro, para famílias que, por norma, enfrentam já dificuldades financeiras (Snyder et al., 2001; Glaze e Maruschak, 2008; Mignon e Ransford, 2012). Assim, e tal como acontece em outros países, as mães sendo as principais cuidadoras dos menores antes da reclusão (como também se verifica neste estudo) acabam por ser as mais prejudicadas quando se trata de manter uma relação pessoal com estes/as descendentes, o que acarreta desvantagens emocionais tanto para elas como para as crianças e adolescentes, como indica a literatura da especialidade (Bayes, 2007; QCEA, 2007; Robertson, 2008). 


\section{Qualidade da relação percebida, prévia e atual, com os/as filhos/as menores}

Avaliou-se, igualmente, a perceção da qualidade da relação com os/as filhos/as menores numa escala de «muito boa» a «muito má», em três vertentes: antes da reclusão, na atualidade e com o atual cuidador. A avaliação desta última dimensão foi considerada relevante, pelo poder destas figuras em facilitar ou dificultar a comunicação e pelas imagens que transferem sobre as figuras parentais.

No que diz respeito ao momento antes da reclusão, salienta-se que foram encontradas diferenças significativas entre homens e mulheres $(U=3992.0, p=$ .011): as reclusas apresentam uma perceção da qualidade da relação superior, numa fase prévia à reclusão (muito boa $-82 \%$ e boa $-10 \%$ ), do que os reclusos (muito boa $-64 \%$ e boa $-31 \%$ ). Quanto à qualidade da relação atual não foram encontradas diferenças entre os sexos.

Comparando, contudo, a qualidade da relação dos/as reclusos/as com os/as descendentes menores, antes e durante a reclusão, verificou-se a presença de diferenças significativas $(Z=-4.56, p \leq .001)$. Desta forma, a qualidade da relação percebida por mães e pais relativamente aos/às menores, durante a reclusão ( $M=$ $3.45, D P=.86)$ é inferior à qualidade percebida desta relação antes da reclusão $(M=3.70, D P=.56)$. Esta diferença verificou-se tanto no caso das mulheres $(Z=$ $-3.31, p=.001)$, como no caso dos homens $(Z=-3.18, p=.001)$.

No que diz respeito à qualidade da relação com a figura cuidadora atual dos/as descendentes, verificou-se que, na maioria dos casos (54\%), esta é uma relação «muito boa». Todavia, parecem existir diferenças significativas entre reclusos e reclusas a este nível, sendo que as mulheres apresentam uma perceção de qualidade da relação superior com os/as atuais cuidadores/as dos/as descendentes $(U=3960.5, p=.046)$, do que os homens.

\section{Competência parental percebida}

A competência parental atual percebida («sente-se um bom pai/uma boa mãe?») de cada um/a dos/as reclusos/as foi bastante positiva e não foram verificadas diferenças entre homens e mulheres a este nível $(U=4586.5, p=.17)$.

Verificou-se a presença de uma correlação positiva marginalmente significativa entre a frequência de telefonemas feitos pelas reclusas aos/às filhos/as e a perceção de competência parental destas $\left(r_{s}=.17, p=.09\right)$. O mesmo se verificou no que se refere às visitas recebidas por estas $\left(r_{s}=.18, p=.07\right)$, de forma que uma maior frequência de visitas recebidas dos/as filhos/as menores tende a associar-se a uma maior perceção de eficácia parental. Constatou-se, também, uma correlação positiva significativa entre a frequência de correspondência enviada, pelas reclusas, aos/às descendentes e a perceção de eficácia parental destas $\left(r_{s}=.21, p=\right.$ .04). Relativamente aos homens, apurou-se que a perceção de competência parental destes não foi associada aos telefonemas feitos aos/às filhos/as menores $\left(r_{s}=\right.$ 
$.10, p=.32)$, às visitas recebidas $\left(r_{s}=.16, p=.11\right)$ ou à correspondência enviada $\left(r_{s}\right.$ $=.14, p=.18)$, parecendo indicar que para estes outras dimensões não comunicacionais permitem apoiar a perceção de eficácia.

As visitas constituíram-se, neste estudo, como a forma de comunicação preferencial para homens e mulheres tendo ambos manifestado desejo de uma comunicação mais frequente salientando-se, assim, o papel essencial destas relações em contexto prisional.

\section{Conclusão}

O Sistema Penal nacional visa a reabilitação e reeducação do/a recluso/a, a sua reinserção bem-sucedida na sociedade e a inexistência de reincidência no crime (Rodrigues, 2002). Neste sentido, a manutenção das relações parentais previamente existentes são de potenciar com vista não só à atenuação dos potenciais efeitos nocivos da separação para ambas as partes, mas também com vista à futura integração social.

Assim, apesar de se verificar uma alteração do modelo tradicional de paternidade e um maior envolvimento da figura masculina na vida doméstica e parental em Portugal (Aboim, 2010), algumas assimetrias de género e definições tradicionais do papel do pai e da mãe ainda se verificam neste estudo. Estas marcas de género parecem mais evidentes no período anterior à reclusão, vivendo as mulheres consideravelmente mais do que os homens com a sua descendência e revelando uma maior perceção de uma boa relação em período anterior à mesma. Outra das diferenças encontrada é a maior dificuldade das mulheres em receberem visitas, quando se encontram a grande distância dos/as seus/suas descendentes e, talvez esta distância explique a maior frequência das mães em escreverem e receberem cartas dos seus filhos ou filhas, como forma de colmatar e diminuir a separação.

No que toca a simetrias, tanto pais como mães evidenciam o desejo de aumentar a comunicação com os/as descendentes no período de reclusão, talvez porque, como indica o trabalho de Rafaela Granja, Manuela Cunha e Helena Machado (2013), os pais tendem a dar um novo significado a paternidade mais próximos dos afetos e da relação.

Verificando-se neste estudo que as crianças vivem mais frequentemente com mães antes destas serem privadas de liberdade e, como tal, as suas rotinas são mais duramente alteradas pela sua reclusão (QCEA, 2007), é também verdade que alguns estudos indicam que os homens das classes socias mais desfavorecidas investem cada vez mais na paternidade para além da dimensão económica, nomeadamente em vertentes sociais e relacionais (Nelson, 2004; Granja, Cunha e Machado, 2013).

Tendo sido as políticas prisionais apontadas pelos/as reclusos/as como o principal obstáculo à comunicação entre ambas as partes, importa repensar algumas modificações que promovam a qualidade da relação entre as pessoas recluí- 
das e descendentes. Uma dessas medidas passaria pela flexibilizando da legislação para que a comunicação telefónica possa ser agilizada, mais frequente e com duração mais alargada. Alguns países facilitam a comunicação por videoconferência, o que seria um meio interessante para diminuir as distâncias físicas reais (Magaletta e Herbst, 2001). Este caso seria especialmente importante para as mães que se encontram mais distantes. Por outro lado, importa tornar as salas de visita em espaços mais agradáveis, acolhedores e adequados, possibilitando a interação num contexto lúdico (Magaletta e Herbst, 2001), tendo em conta que atualmente as prisões portuguesas parecem levar em pouca consideração as visitas das crianças (QCEA, 2007).

Salienta-se, por fim, que em alguns países, como Austrália (Dawson, Jackson e Nyamathi, 2012) e E. U. A. (Scott, 1998) são conduzidos programas destinados a reclusos/as com crianças e jovens menores, de forma a dotarem-nos/as de competências parentais mais eficazes. Alguns destes programas incluem a participação das próprias crianças e jovens da população reclusa, para que sentimentos mais negativos possam ser expressos, permitindo laços mais equilibrados de parte a parte (Scott, 1998).

\section{Bibliografia}

Aboim, Sofia (2010), «Género, família e mudança em Portugal», in Karin Wall, Sofia Aboim e Vanessa Cunha (org.), A Vida Familiar no Masculino: Negociando Velhas e Novas Masculinidades, Lisboa, Comissão para a Igualdade no Trabalho e no Emprego, 39-66.

Badinter, Elisabeth (1985), Um amor conquistado: O mito do amor materno, Rio de Janeiro, Nova Fronteira.

Bayes, Shawn (2008), «Acknowledging and Reaching Children of Prisoners», Canadian Children Child Study 32(1), 9-15.

Cohen, Sheldon; Wills, Thomas Ashby (1985), «Stress, social support, and the buffering hypothesis», Psychology Bulletin 98, 310-357.

Collier, Richard; Sheldon, Sally (2008), Fragmenting Fatherhood. A Socio-Legal Study, Oregon, Hart Publishing.

Chui, Wing (2010), «Pains of imprisonment: Narratives of the women partners and children of the incarcerated», Child and Family Social Work 15(2), 196-205.

Cunha, Manuela Ivone (1994), Malhas que a reclusão tece. Questões de identidade numa prisão feminina, Lisboa, Centro Estudos Judiciários.

Cunningham, Alison; Baker, Linda (2003), Waiting for mommy: Giving a voice to the hidden victims of imprisonment, London, Canada, Centre for Children and Families in the Justice System.

Cutrona, Carolyn E.; Cole, Valerie; Colangelo, Nicholas; Assouline, Susan G.; Russel, Daniel W. (1994), «Perceived parental social support and academic achievement: An attachment theory perspective», Journal of Personality and Social Psychology 66(2), 369$-378$.

Dallaire, Daniele; Ciccone, Anne; Wilson, Laura (2010), «Teachers' experiences with and expectations of children with incarcerated parents», Journal of Applied Developmental Psychology 31(4), 281-290. 
Dawson, Angela, Jackson, Debra, Nyamathi, Adeline (2012), "Children of incarcerated parents: Insights to addressing a growing public health concern in Australia», Children and Youth Services Review 34, 2433-2441.

Decreto-Lei n.․ 51/2011 de 11 de abril. Diário da República, 1ํㅗㄹérie, N. 71 .

Folk, Johanna B.; Nichols, Emily Bebber; Dallaire, Danniel; Loper, Ane (2012), «Evaluating the content and reception of messages from incarcerated parents to their children", American Journal of Orthopsychiatry 82(4), 529-541.

Glauber, Rebecca; Gozjolko, Kristi (2011), «Do traditional fathers always work more? Gender, Ideology, Race, and Parenthood", Journal of Marriage and Family 73, 1133-1148.

Glaze, Lauren; Maruschak, Laura (2008), Parents in prison and their minor children, Washington, DC, U.S. Department of Justice, Bureau of Justice Statistics.

Geller, Amanda; Garfinkel, Irwin; Cooper, Carey; Mincy, Ronald (2009), «Parental incarceration and child well-being: Implications for urban families», Social Science Quarterly 90(5), 1186-1202.

Goffman, Erving (1961), Asylums: Essays on the social situation of mental patients and other inmates, Garden City, Anchor Books.

Granja, Rafaela; Cunha, Manuela I.; Machado, Helena (2013), «Formas alternativas de exercício da parentalidade e maternidade em contexto prisional», ex aequo 28, 73-86.

Lanier, Charles (1993), Affective states of fathers in prison, Justice Quarterly 10 (1), 49-66.

Lee, Chang-Bae, Sansone, Frank; Swanson, Cheryl; Tatum, Kimberly (2012), «Incarcerated fathers and parenting: Importance of the relationship with their children», Social Work in Public Health 27(1-2), 165-186.

Loper, Anne; Carlson, L. Wrenn; Levitt, Levitt; Scheffel, Kathryn (2009), «Parenting stress, alliance, child contact, and adjustment of imprisoned mothers and fathers», Journal of Offender Rehabilitation 48(6), 483-503.

Machado, Helena; Granja, Rafaela (2013), «Paternidades fragmentadas. Género, emoções e (des)conexões biogenéticas e prisionais», Análise Social XLVIII (30), 552-571.

Magaletta, Philip R.; Herbst, Dominique (2001) «Fathering from prison: Common struggles and successful solutions», Psychotherapy 38 (1), 88-96.

Maldonado, Solangel (2006), «Recidivism and paternal engagement», Family Law Quarterly, 40 (2), 191-211.

Mignon, Sylvia; Ransford, Paige (2012), «Mothers in prison: Maintaining connections with children", Social Work in Public Health 27(1-2), 69-88.

Miller, Keva (2006), «The Impact of parental incarceration on children: An emerging need for effective interventions», Child and adolescent Social Work Journal 23(4), 472-486.

Mumola, Christopher (2000), Incarcerated parents and their children (NCJ-182335), Washington, DC, U.S. Department of Justice, Bureau of Justice Statistics.

Murray, Joseph; Farrington, David P.; Sekol, Ivana; Olsen, Rikke F. (2009), «Effects of parental imprisonment on child antisocial behavior and mental health: A systematic review», Campbell Systematic Reviews 4, 1-105.

Nelson, Timothy J. (2004), «Low-income fathers», Annual Review of Sociology 30, 427-51.

Novais, Filipa; Ferreira, Joaquim; Santos, Eduardo (2010), «Transição e ajustamento de reclusos ao estabelecimento prisional», Psychologica 52, 209-241.

Philips, Susan; Gates, Trevor (2011), «A conceptual framework for understanding the stigmatization of children of incarcerated parents», Journal of Child and Family Studies 20(3), 286-294.

Quaker Council for European Affairs (QCEA) (2007), Women in Prison: A Review of the Conditions in Member States of the Council of Europe, Brussels, QCEA. 
Robertson, Oliver (2008), Children imprisoned by circumstance, Geneva, Quaker United Nations Office.

Rodrigues, Anabela M. (2002), Novo olhar sobre a questão penitenciária: estatuto jurídico do recluso e socialização, jurisdicionalização, consensualismo e prisão, Coimbra, Coimbra Editora.

Rosenberg, Jennifer (2009), Children Need Dads Too: Children with Fathers in Prison, Geneva, Quaker United Nations Office.

Rich, Adrienne (1976), Of woman born. Motherhood as experience and institution, New York, Norton \& Company.

Sarason, Irving; Levine, Henry; Basham, Robert; Sarason, Barbara (1983), «Assessing social support: The Social Support Questionnaire», Journal of Personality and Social Psycho$\log y 44$ (1), 127-139.

Scott, Edward M. (1998), Within the hearts and minds of prisoners, Springfield, IL, Charles C. Thomas.

Serras, Dinora; Pires, António (2004), «Maternidade atrás das grades», Análise Psicológica XXII (2), 413-425.

Snyder, Zoan; Carlo, Teresa; Coats, Megan (2001), «Parenting from prison: An examination of a children's visitation program at a women's correctional facility», Marriage $\mathcal{E}$ Family Review 32(3-4), 33-61.

Swanson, Cheryl; Lee, Chang; Sansone, Frank; Tatum, Kimberley (2012), «Prisoner's perceptions of father-child relationships and social support», American Journal of Criminal Justice 37, 338-355.

Tebo, Margaret (2006), «A parent in prison», ABA Journal 92 (2), 12-13.

Tuerk, Elen; Loper, Ann (2006), «Contact between incarcerated mothers and their children», Journal of Offender Rehabilitation 43 (1), 23-43.

Walmsley, Roy (2013), World prison population list (9 ${ }^{\text {th }}$ ed.), London, International Centre for Prison Studies, University of Essex.

Wacquant, Loic (2004), As prisões da miséria, [em linha] Disponível em http:// www.fesppr.br/ daiane/Artigos\%20de\%20Sociologia\%20Jur\%EDdica/ 2 WACQUANT Loic Prisoes da Miseria Redistribudo por BPI.pdf [consultado em 12 janeiro de 2014].

Wall, Karin (2010), «Os homens e a política de família», in Karin Wall, Sofia Aboim e Vanessa Cunha (org.), A Vida Familiar no Masculino: Negociando Velhas e Novas Masculinidades, Lisboa, CITE, 67-94.

Wall, Karin; Aboim, Sofia; Marinho, Sofia (2007), «Fatherhood, family and work in men's lives: negotiating new and old masculinities», Recherches Sociologiques et Anthropologiques 38 (2), 105-122.

Catarina Vieira. Mestre em Psicologia da Justiça, fez estágio com jovens e famílias em risco. Os seus interesses de investigação dizem respeito à área de jovens e adultos ofensores, nomeadamente às questões relativas à maternidade e paternidade em reclusão, procurando compreender como as construções sociais de género são vivenciadas em contexto prisional. catarina.vieira.90@hotmail.com

Luísa Saavedra. Professora Auxiliar do Departamento de Psicologia Aplicada da Escola de Psicologia, Universidade do Minho. É doutorada em Psicologia e tem lecionado e investigado na área do género e perspetivas feministas, mais recentemente na área da criminologia e justiça criminal. Nesta área tem-se dedicado essen- 
cialmente às mulheres ofensoras, nomeadamente no domínio da maternidade e paternidade em reclusão. Estes trabalhos têm dado origem a teses e a diversos artigos nacionais e internacionais. Tem participado, com a CIG, em ações e publicações. lsaavedra@psi.uminho.pt

Alexandra M. Araújo. Doutorada em Psicologia e Investigadora no Instituto de Educação da Universidade do Minho, com financiamento pela Fundação para a Ciência e Tecnologia (SFRH/BPD/85856/2012). É especialista em investigação quantitativa e tem publicado numerosos artigos nacionais e internacionais na área da educação e no seu cruzamento com as questões de género.

alexandra.araujom@gmail.com

Escola de Psicologia (EPSI) da Universidade do Minho, Campus de Gualtar 4710-057 Braga, Portugal.

Artigo recebido em 30 de agosto de 2014 e aceite para publicação em 22 de outubro de 2014. 